\title{
Scanning Electron Microscopic Evaluation of Smear Layer Removal Ability of Novel Irrigant QMix compared with Others at Apical Third of the Root
}

\author{
${ }^{1}$ Sreeha K Kolanu, ${ }^{2}$ Arun K Patnana, ${ }^{3}$ Bolla Nagesh, ${ }^{4}$ Phani HD Vaaka, ${ }^{5}$ Swapnika Polineni
}

\begin{abstract}
Aim: The success of an endodontic treatment depends on the complete elimination of the microorganisms from the root canal system for which effective eradication of smear layer is crucial. Hence, various final irrigating solutions were introduced in endodontics. The aim of this in vitro study is to compare the smear layer removal efficacy of different final irrigating solutions at the apical third of the root canal through scanning electron microscopic (SEM) image analysis.
\end{abstract}

Materials and methods: Forty human single-rooted mandibular premolar teeth were taken and decoronated to standardize the canal length. Each tooth was prepared endodontically with same chemomechanical technique and the teeth were randomly divided into four groups based on the final irrigation regimen. Group I: saline, group II: Tubulicid Plus, group III: BioPure MTAD, and group IV: QMix. After final irrigation, SEM evaluation was done for the assessment of removal of the smear layer at apical third, and data were analyzed using the Kruskal-Wallis test and Mann-Whitney $U$ test.

Results: Intergroup comparison of the groups showed statistically significant differences in the smear layer removal efficacy of irrigating solutions tested. QMix is most effective in the removal of smear layer when compared with other tested irrigating solutions.

Conclusion: QMix is the most effective final irrigating solution for smear layer removal followed by MTAD and Tubulicid Plus.

Clinical significance: Final irrigating solution plays a major role in the elimination of smear layer, thereby enhancing the

\footnotetext{
${ }^{1}$ Department of Conservative Dentistry and Endodontics, KIMS Dental College and Hospital, Amalapuram, Andhra Pradesh India

${ }^{2}$ Department of Dentistry, All India Institute of Medical Sciences Jodhpur, Rajasthan, India

${ }^{3}$ Department of Conservative Dentistry and Endodontics, Sibar Institute of Dental Sciences, Guntur, Andhra Pradesh, India

${ }^{4}$ Department of Oral and Maxillofacial Surgery, KIMS Dental College and Hospital, Amalapuram, Andhra Pradesh, India

${ }^{5}$ Department of Conservative Dentistry and Endodontics, CKS Teja Institute of Dental Sciences, Tirupati, Andhra Pradesh India

Corresponding Author: Sreeha K Kolanu, Department of Conservative Dentistry and Endodontics, KIMS Dental College and Hospital, Amalapuram, Andhra Pradesh, India, Phone: +919010477996, e-mail: sreeha.bds@gmail.com
}

hermetic seal of obturating materials, resulting in greater success rate of root canal treatment. Further research is required regarding the use of QMix on smear layer removal and also its effect on ultrastructural changes in dentin.

Keywords: Laboratory research, MTAD, QMix, Root canal irrigation, Scanning electron microscopy, Smear layer, Tubulicid Plus.

How to cite this article: Kolanu SK, Patnana AK, Nagesh B, Vaaka PHD, Polineni S. Scanning Electron Microscopic Evaluation of Smear Layer Removal Ability of Novel Irrigant QMix compared with Others at Apical Third of the Root. World J Dent 2018;9(3):220-224.

Source of support: Nil

Conflict of interest: None

\section{INTRODUCTION}

The success of endodontic treatment depends on the complete three-dimensional sealing of the root canal system. ${ }^{1}$ Even after meticulous care, cleaning and shaping procedures with various root canal instruments leave an amorphous, granular, and irregular layer covering root canal dentin known as smear layer. ${ }^{2}$

The smear layer is composed of both organic and inorganic substances, such as microorganisms, odontoblastic processes, and necrotic material covering the root canal walls and openings of the dentinal tubules. ${ }^{3}$ It acts as a barrier for the effective penetration of intracanal medicaments and sealers into the dentinal tubules. ${ }^{4,5}$ In addition, it may increase postobturation microleakage and may serve as a source of nutrients for some species of intracanal microbiota. ${ }^{6,7}$

For smear layer removal, various irrigating solutions, such as citric acids, phosphoric acid, sodium hypochlorite, ethylenediaminetetraacetic acid (EDTA), EDTA plus Cetavlon, and carbamide peroxide have been used. ${ }^{8}$

Several other new irrigating agents like MTAD, ${ }^{9}$ $\mathrm{QMix}^{10}$ have been introduced as final irrigating solutions for effective smear layer removal.

The present study aimed to evaluate the smear layer removal ability of different final irrigating solutions in the apical third. 


\section{MATERIALS AND METHODS}

\section{Sample Collection}

Forty freshly extracted human mandibular premolars with straight single roots and closed apices were collected. The teeth were immersed in $5.25 \% \mathrm{NaOCl}$ for 1 hour. After obtaining periapical radiographs, all teeth with external or internal root resorption, calcification, complicated root canal anatomy, and previous root canal treatment were excluded. Sample teeth were decoronated to get a stable reference point and standardize the root canal length to $14 \mathrm{~mm}$.

\section{Root Canal Instrumentation}

Patency of the root canal is established by passing a \#10 K-file (K-endo company) into the canal and the working length is determined by subtracting $1 \mathrm{~mm}$ from the total length of the remaining root by passing $10 \mathrm{k}$ file just beyond apex.

All teeth were instrumented using nickel-titanium ProTaper rotary files (Dentsply Mallifer, Ballaigues, Switzerland) with the crown-down technique and an electric speed/torque controller device (X-SMART, Dentsply, Maillefer, Ballaigues, Switzerland). Root canal preparation was done by SX and S1 files in the cervical third, in the middle third by S2 file, and by F1, F2, and F3 finishing files up to the entire working length. Root canals were irrigated with $3 \% \mathrm{NaOCl}$ (Vishal dentocare Pvt. Ltd) in between instrumentation. Then, the samples were divided randomly into four groups based on the final irrigating solutions. Group I: saline, group II: Tubulicid Plus (Dental Therapeutics AB, Sweden), group III: BioPure MTAD (DENTSPLY Tulsa Dental, Tulsa, OK), and group IV: QMix (Dentsply Tulsa Dental Specialities, Tulsa, OK). The final irrigating solutions' effect on root canal surfaces after

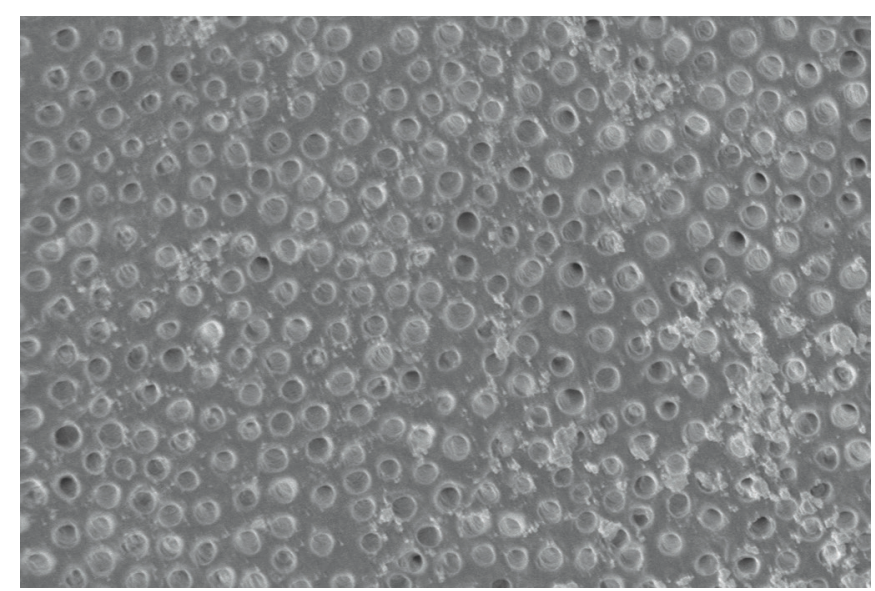

Fig. 1: Scanning electron microscopic image of sample treated with saline instrumentation was determined by treating the canals with $5 \mathrm{~mL}$ of the irrigating solution for 3 minutes. The irrigating solution was delivered using a 30 -gauge sidevented needle (Dentsply Tulsa Dental, Tulsa, Oklahoma, USA) passively placed within the middle third of the root canals. The canals were then dried with paper points. Thereafter, nonpenetrating grooves were made in all specimen teeth at the cementoenamel junction and longitudinally on the buccal and lingual aspects. The teeth were then longitudinally split into two halves and the half containing the greater part of the apex was selected as the representative sample, and they were evaluated under SEM.

\section{Scanning Electron Microscopic Evaluation}

Coded samples were mounted on metallic stubs, gold sputtered, and viewed under an SEM. Photographs at magnifications of $1,000 \times$ were taken for each specimen in the apical third ( $4 \mathrm{~mm}$ from root apex) and then analyzed for the amount of smear layer present. The amount of smear layer remaining on the surface of the root canal and dentinal tubules was scored according to a three-score system developed by Torabinejad et al. ${ }^{9}$

Score 1: no smear layer: no smear layer was detected on the surface of the root canal and all tubules were open.

Score 2: moderate smear layer: no smear layer on root canal walls but tubules contained debris.

Score 3: heavy smear layer: smear layer covered the root canal wall surface and the tubules.

The SEM images of four different group samples showing a various amount of smear layer on dentinal tubules are seen in Figures 1 to 4 . Dentinal tubules free of smear layer were seen in specimens treated with QMix, whereas completely blocked tubules were seen in specimens treated with saline.

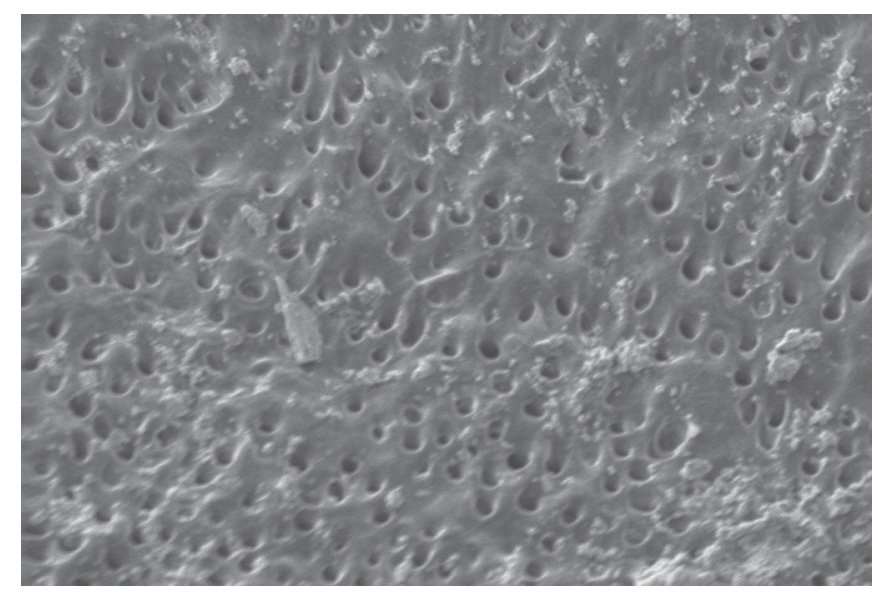

Fig. 2: Scanning electron microscopic image of sample treated with Tubulicid Plus 


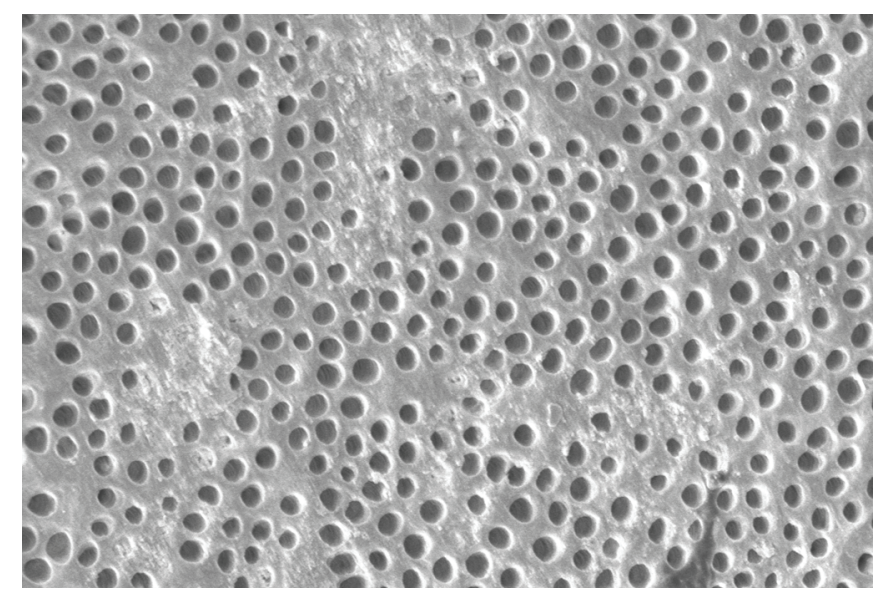

Fig. 3: Scanning electron microscopic image of sample treated with MTAD

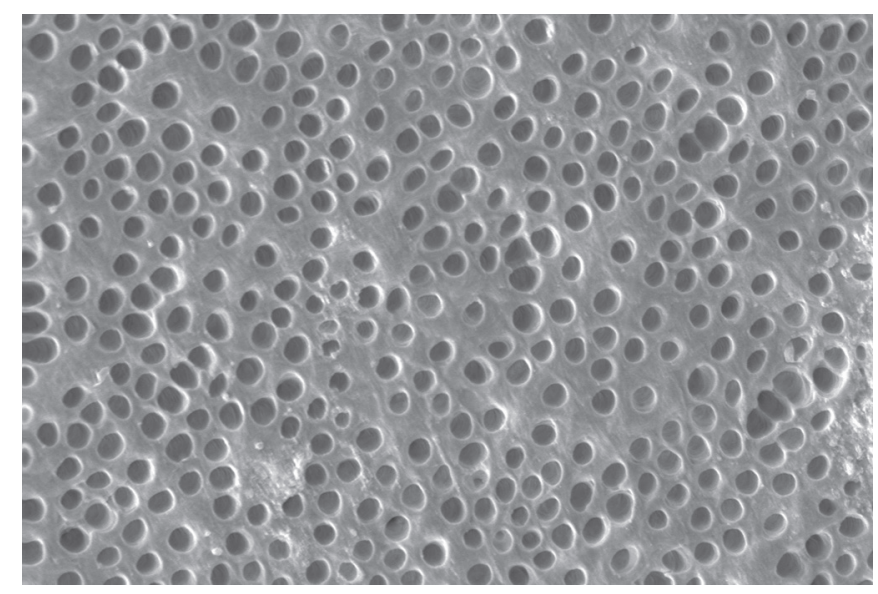

Fig. 4: Scanning electron microscopic image of sample treated with QMix

Table 1: Statistical analysis using Kruskal-Wallis $\mathrm{H}$ test

\begin{tabular}{lllllll}
\hline Group & Min & Max & Mean & $S D$ & $h$-value & $p$-value \\
\hline Group I = saline & 3 & 3 & 3.00 & 0.00 & 30.270 & 0.000 , significant \\
Group II = Tubulicid plus & 2 & 3 & 2.40 & 0.52 & & \\
Group III = MTAD & 2 & 2 & 2.00 & 0.00 & & \\
Group IV = QMix & 1 & 2 & 1.30 & 0.48 & & \\
\hline
\end{tabular}

SD: Standard deviation; Statistically significant if $p<0.05$

Table 2: Comparison between groups: statistical analysis using Mann-Whitney $U$ test

\begin{tabular}{|c|c|c|c|c|c|c|}
\hline Comparison between & $\begin{array}{l}\text { Min } \\
\text { score }\end{array}$ & $\begin{array}{l}\text { Max } \\
\text { score }\end{array}$ & $\begin{array}{l}\text { Mean } \pm S D \\
\text { score }\end{array}$ & $\begin{array}{l}\text { Score difference } \\
\text { mean } \pm S D\end{array}$ & u-value & $p$-value \\
\hline Group I = saline & 3 & 3 & $3.00 \pm 0.00$ & $0.60 \pm 0.00$ & 20.000 & 0.004, significant \\
\hline Group II = Tubulicid plus & 2 & 3 & $2.40 \pm 0.52$ & & & \\
\hline Group I = saline & 3 & 3 & $3.00 \pm 0.00$ & $1.00 \pm 0.00$ & 0.000 & 0.000 , significant \\
\hline Group III = MTAD & 2 & 2 & $2.00 \pm 0.00$ & & & \\
\hline Group I = saline & 3 & 3 & $3.00 \pm 0.00$ & $1.70 \pm 0.48$ & 0.000 & 0.000 , significant \\
\hline Group IV = QMix & 1 & 2 & $1.30 \pm 0.48$ & & & \\
\hline Group II = Tubulicid Plus & 2 & 3 & $2.40 \pm 0.52$ & $0.40 \pm 0.52$ & 30.000 & 0.029 , significant \\
\hline Group III = MTAD & 2 & 2 & $2.00 \pm 0.00$ & & & \\
\hline Group II = Tubulicid Plus & 2 & 3 & $2.40 \pm 0.52$ & $1.10 \pm 0.04$ & 9.000 & 0.001 , significant \\
\hline Group IV = QMix & 1 & 2 & $1.30 \pm 0.48$ & & & \\
\hline Group III = MTAD & 2 & 2 & $2.00 \pm 0.00$ & $0.70 \pm 0.48$ & 15.000 & 0.001, significant \\
\hline Group IV = QMix & 1 & 2 & $1.30 \pm 0.48$ & & & \\
\hline
\end{tabular}

SD: Standard deviation; Statistically significant if $p<0.05$

\section{RESULTS}

Statistical analysis was done using software version Statistical Package for the Social Sciences 17.0 version (SPSS Inc., Chicago) by using Kruskal-Wallis H test and Mann-Whitney U test. Smear layer scores of four experimental groups showing statistically significant values are seen (Table 1) where $p$ is taken as 0.05 . The results showed that group IV showed the least smear layer scores $(1.30 \pm 0.48)$ when compared with others. This was followed by group III ( $2.00 \pm 0.00)$, group II ( 2.40 \pm 0.52 ), and group I, which showed the highest smear layer scores $(3.00 \pm 0.00)$. Comparison among groups in which all of them showed significant values is statistically presented in Table 2 .

\section{DISCUSSION}

The root canal system shows various patterns and complexities in different roots and regions of the root. The dentinal tubules are irregular in density and direction in the apical region of roots. ${ }^{11,12}$

It is nearly impossible for the instrument to penetrate lateral canals and isthmuses present in root apex due to the limited space, low permeability, and complex anatomical configuration. Apical instrumentation poses a 
challenge in endodontic therapy and can only be cleaned by effective antimicrobial irrigation. ${ }^{11,12}$

Smear layer removal is less predictable in the apical region due to smaller dimensions in apical canal obstructing the effective penetration of irrigants and resulting in limited contact between canal wall and irrigants. ${ }^{13}$

Penetration of irrigating solutions in the apical third of the root canal can be increased by using newer irrigants, which are available with the addition of surfactants that increase the wettability of the solution on solid dentin due to their low surface tension, which in turn increases the efficacy of irrigating solution in the narrow apical region of the root. ${ }^{14}$

In this study, three final irrigating solutions were used. Among these, QMix showed better smear layer removal when compared with others.

QMix is a new root canal irrigating solution containing a mixture of an antimicrobial agent bisbiguanide, a polyamino carboxylic acid calcium-chelating agent, saline and a surfactant. ${ }^{15}$

These results are supported by the study conducted by Eliot et $\mathrm{al}^{16}$ who evaluated the effectiveness of the three different formulations of QMix on the removal of canal wall smear layer compared with EDTA through SEM analysis and concluded that QMix is more efficient than EDTA.

These results were also supported by studies done by Stojicic et al, ${ }^{17}$ Ballal et al, ${ }^{18}$ and Dai et al. ${ }^{19}$

BioPure MTAD introduced by Toranbinejad and Johnson in 2003 at the Loma Linda University is a mixture of tetracycline isomer ( $3 \%$ doxycycline), $4.25 \%$ citric acid, and detergent (Tween 80). It has smear layer removal efficacy and antimicrobial properties. In this product, to increase the water solubility, doxycycline hyclate is used in it instead of its free base, doxycycline monohydrate. ${ }^{20}$

In this study, MTAD is shown to be effective next to QMix in removing the smear layer. It may be due to its low surface tension $\left(34.5 \mathrm{~mJ} / \mathrm{m}^{2}\right)$, resulting in greater wettability. ${ }^{21}$

These results correlate with the study conducted by Paul et $\mathrm{al}^{22}$ who showed the ability of MTAD to remove the smear layer in the apical third of the root effectively compared with EDTA, EDTA with ultrasonification, and citric acid.

Tubulicid Plus is an effective smear layer-removing agent and consists of cocoamphodiacetate, benzalkonium chloride, disodium edetate dihydrate, phosphate buffer solution, and aqua dest. It has greater wettability due to additives which decrease its viscosity and surface tension. ${ }^{23}$

Liolios et $\mathrm{al}^{23}$ showed that Largal Ultra and Tubulicid Plus removed considerable amounts of smear layer regardless of the method of instrumentation. However, in this study, Tubulicid Plus showed the least smear layer removal when compared with MTAD and QMix.

\section{CONCLUSION}

Within the limitations of this study, QMix 2 in 1 displayed effective smear layer removal when compared with Tubulicid Plus, MTAD, and saline. Other final irrigating solutions in the study showed significant differences. The MTAD showed better efficacy than Tubulicid Plus.

\section{REFERENCES}

1. Violich DR, Chandler NP. The smear layer in endodontics-a review. Int Endod J 2010 Jan;43(1):2-15.

2. Heard F, Walton RE. Scanning electron microscope study comparing four root canal preparation techniques in small curved canals. Int Endod J 1997;30:323-331.

3. Pashley DH. Smear layer: overview of structure and function. Proc Finn Dent Soc 1992;88 (Suppl 1):215-224.

4. Economides N, Liolios E, Kolokuris I, Beltes P. Long-term evaluation of the influence of smear layer removal on the sealing ability of different sealers. J Endod 1999 Feb;25(2): 123-125.

5. Saunders WP, Saunders EM. Influence of smear layer on the coronal leakage of thermafil and laterally condensed guttapercha root fillings with a glass ionomer sealer. J Endod 1994 Apr;20(4):155-158.

6. Brannstrom M. Smear layer: pathological and treatment considerations. Oper Dent (Suppl) 1984;3:35-42.

7. Pashley DH. Smear layer: physiological considerations. Oper Dent (Suppl) 1984;3:13-29.

8. Torabinejad M, Handysides R, Khademi AA, Bakland LK. Clinical implications of the smear layer in endodontics: a review. Oral Surg Oral Med Oral Pathol Oral Radiol Endod 2002 Dec;94(6):658-666

9. Torabinejad M, Khademi AA, Babagoli J, Cho Y, Johnson WB, Bozhilov K, Kim J, Shabahang S. A new solution for the removal of the smear layer. J Endod 2003 Mar;29(3):170-175.

10. Kara Tuncer A, Tuncer S, Siso SH. Effect of Qmix irrigant on microhardness of dentine. Aust Dent J 2015 Jun;60(2):163-168.

11. McComb D, Smith DC. A preliminary scanning electron microscopic study of rootcanals after endodontic procedures. J Endod 1975 Jul;1(7):238-242.

12. Moodnik RM, Dorn SO, Feldman MJ, Meadow E, Levely M, Borden BG. Efficacy of biomechanical instrumentation: a scanning electron microscopic study. J Endod 1976 Sep;2(9): 261-266.

13. Lui JN, Kuah HG, Chen NN. Effect of EDTA with and without surfactants or ultrasonics on removal of smear layer. J Endod 2007;33:472-475.

14. Kuah HG, Lui JN, Tseng PS, Chen NN. The effect of EDTA with and without ultrasonics on removal of the smear layer. J Endod 2009;35:393-396.

15. Chandrasekhar V, Amulya V, Rani VS, Prakash TJ, Ranjani AS, Gayathri Ch. Evaluation of biocompatibility of a new root canal irrigant QMix ${ }^{\mathrm{TM}} 2$ in 1 -an in vivo study. J Conserv Dent 2013 Jan;16(1):36-40.

16. Eliot C, Hatton JF, Stewart GP, Hildebolt CF, Jane Gillespie M, Gutmann JL. The effect of the irrigant QMix on removal of 
canal wall smear layer: An ex vivo study. Odontology 2014 Jul;102(2):232-240.

17. Stojicic S, Shen Y, Qian W, Johnson B, Haapasalo M. Antibacterial and smear layer removal ability of a novel irrigant, QMiX. Int Endod J 2012;45:363-371.

18. Ballal NV, Tweeny A, Khechen K, Prabhu KN, Satyanarayan, Tay FR. Wettability of root canal sealers on intraradicular dentine treated with different irrigating solutions. J Dent 2013 Jun;41(6):556-560.

19. Dai L, Khechen K, Khan S, Gillen B, Loushine BA, Wimmer CE, Gutmann JL, Pashley D, Tay FR. The effect of QMix, an experimental antibacterial root canal irrigant, on removal of canal wall smear layer and debris. J Endod 2011 Jan;37(1): 80-84.
20. Singla MG, Garg A, Gupta S. MTAD in endodontics: an update review. Oral Surg Oral Med Oral Pathol Oral Radiol Endod 2011 Sep;112(3):e70-e76.

21. VemuriS, KolanuSK, VarriS, Pabbati RK, Penumaka R, Bolla N. Effect of different final irrigating solutions on smear layer removal in apical third of root canal: a scanning electron microscope study. J Conserv Dent 2016 Jan-Feb;19(1):87-90.

22. Paul ML, Mazumdar D, Niyogi A, Baranwal AK. Comparative evaluation of the efficacy of different irrigants including MTAD under SEM. J Conserv Dent 2013;16:336-341.

23. Liolios E, Economides N, Parissis-Messimeris S, Boutsioukis A. The effectiveness of three irrigating solutions on root canal cleaning after hand and mechanical preparation. Int Endod J 1997 Jan;30(1):51-57. 